\title{
Family-based mitochondrial association study of traits related to type 2 diabetes and the metabolic syndrome in adolescents
}

\author{
E. M. Byrne • A. F. McRae • D. L. Duffy • Z. Z. Zhao • \\ N. G. Martin • J. B. Whitfield • P. M. Visscher • \\ G. W. Montgomery
}

Received: 3 October 2008 / Accepted: 6 July 2009 / Published online: 4 September 2009

(C) Springer-Verlag 2009

\begin{abstract}
Aims/hypothesis There has been much focus on the potential role of mitochondria in the aetiology of type 2 diabetes and the metabolic syndrome, and many casecontrol mitochondrial association studies have been undertaken for these conditions. We tested for a potential association between common mitochondrial variants and a number of quantitative traits related to type 2 diabetes in a large sample of $>2,000$ healthy Australian adolescent twins and their siblings, many of whom were measured on more than one occasion.

Methods To the best of our knowledge, this is the first mitochondrial association study of quantitative traits undertaken using family data. The maternal inheritance pattern of mitochondria means established association methodologies are unsuitable for analysis of mitochondrial data in families. We present a methodology, implemented in the freely available program Sib-Pair for performing such an analysis.
\end{abstract}

Electronic supplementary material The online version of this article (doi:10.1007/s00125-009-1510-9) contains supplementary material, which is available to authorised users.

E. M. Byrne $(\bowtie) \cdot$ A. F. McRae $\cdot$ P. M. Visscher

Queensland Statistical Genetics,

Queensland Institute of Medical Research,

300 Herston Road,

Brisbane, QLD 4029, Australia

e-mail: enda.byrne@qimr.edu.au

E. M. Byrne

School of Medicine, University of Queensland,

Brisbane, QLD, Australia

D. L. Duffy $\cdot$ Z. Z. Zhao $\cdot$ N. G. Martin • J. B. Whitfield

G. W. Montgomery

Genetic Epidemiology, Queensland Institute of Medical Research,

Brisbane, QLD, Australia
Results Despite our study having the power to detect variants with modest effects on these phenotypes, only one significant association was found after correction for multiple testing in any of four age groups. This was for mt14365 with triacylglycerol levels (unadjusted $p=0.0006$ ). This association was not replicated in other age groups. Conclusions/interpretation We find little evidence in our sample to suggest that common European mitochondrial variants contribute to variation in quantitative phenotypes related to diabetes. Only one variant showed a significant association in our sample, and this association will need to be replicated in a larger cohort. Such replication studies or future meta-analyses may reveal more subtle effects that could not be detected here because of limitations of sample size.

Keywords Australian - Diabetes $\cdot$ Mitochondria $\cdot$ Twins

\begin{tabular}{ll}
\multicolumn{2}{l}{ Abbreviations } \\
ALT & Alanine aminotransferase \\
GGT & $\gamma$-Glutamyltransferase \\
mtDNA & Mitochondrial DNA \\
OXPHOS & Oxidative phosphorylation \\
SNP & Single-nucleotide polymorphism
\end{tabular}

Introduction

The central role of mitochondria in metabolism has led to much effort to uncover their potential role in the metabolic syndrome and type 2 diabetes mellitus. The primary role of mitochondria is to produce energy in the form of ATP by oxidative phosphorylation. The mitochondrial DNA (mtDNA) encodes 13 proteins, all of which are subunits of the 
energy-generating oxidative phosphorylation (OXPHOS) complexes. Several lines of evidence suggest that mtDNA is central to the aetiology of diabetes. Defects in OXPHOS are nearly always found in type 2 diabetes, particularly in the aged and in offspring of type 2 diabetes patients $[1,2]$. Genes involved in OXPHOS are also expressed at lower levels in type 2 diabetes patients than healthy controls [3, 4]. The link between glucose recognition and insulin secretion by pancreatic beta cells depends on metabolic changes and signal generation within mitochondria [5]. It has been noted that fewer mitochondria can be seen microscopically in diabetes patients than in controls, and those that can be seen are smaller than normal [6]. Mitochondrial variants have been indirectly linked with diabetes by the observation that there is a bias towards maternal transmission of diabetes, which increases with mean age of onset [7].

More direct evidence comes from the observation that there are more than 40 diseases caused by mtDNA mutations that involve hyperglycaemia [8]. The A3243G mutation, when found in only a small fraction of mitochondria in the cell is known to cause maternally inherited diabetes and deafness [9]. This is the most common known molecular cause of diabetes worldwide, accounting for $1 \%$ of all cases of type 2 diabetes. This mutation is in a mitochondrial leucine tRNA. As the fraction of mutant mitochondria increases, so does the severity of the associated metabolic disease, with mitochondrial myopathy, encephalopathy, lactic acidosis and stroke-like episodes (MELAS) being the most severe. Mitochondria may also play a role in the metabolic syndrome, as evidenced by a mutation in the $t R N A^{I L E}$ gene (also known as MT-TI) at nucleotide position 4,291 causing hypertension, hypercholesterolaemia and hypomagnesaemia [10]. A recent study using rats with identical nuclear genomes but differing mitochondria showed that mitochondrial variants have a direct effect on a number of metabolic phenotypes, including triacylglycerol levels [11].

The large amount of evidence for mitochondrial variants contributing to diabetes risk has led to a number of association studies being undertaken. These have included both case-control studies of type 2 diabetes and studies on metabolic traits that are known risk factors for diabetes. More than 25 mitochondrial variants have been posited as being associated with type 2 diabetes [7, 12], but in general there have been conflicting findings regarding potential associations. A large study in the UK population using 500 cases and controls showed an association with the T16189C polymorphism, which is found at a frequency of $6-10 \%$ in Europe [13]. This finding was replicated in the Asian population by two separate studies [14, 15]. However, a meta-analysis of studies in European populations suggested it was unlikely that the region containing the mt16189 polymorphism played a role in increasing susceptibility to type 2 diabetes [16]. One of the largest studies to date, carried out in the Finnish population, confirmed the association with mt16189, and also reported a weak association with haplogroup J [17]. This is the first reported association with a major haplogroup. Some earlier studies reported no associations with major haplogroups, but suffered from small sample sizes, particularly for certain haplogroups [18]. The association with haplogroup $\mathrm{J}$ was supported by a study in a white Brazilian population, which also found an association with haplogroup T [19]. More recently, there has been a report that haplogroup N9a confers resistance to type 2 diabetes in Asians [20]. In the largest association study to date [21], an association between both diabetes disease status and related metabolic traits and common European mitochondrial variants was tested for in several populations of European origin. The only significant association found for increased risk of diabetes was mt12612 in the Polish sample. No significant associations were found for any of the metabolic traits in non-diabetic individuals. Previous mitochondrial association studies of type 2 diabetes and the metabolic syndrome are summarised in Table 1. It should be noted that this table is not an exhaustive list of mitochondrial association studies and that further small-scale studies have been carried out.

A previous association study [21] was, to the best of our knowledge, the first to look at the potential role of mitochondria in quantitative metabolic traits related to type 2 diabetes. Our study examines whether common mitochondrial variants contribute to variation in a larger number of biochemical traits in healthy adolescent twins. The traits examined include plasma lipids, HDL-cholesterol and triacylglycerol, which are known risk factors for cardiovascular disease and the metabolic syndrome [22]. Twin studies have shown these traits to be highly heritable, with higher estimates in younger samples than older ones [23]. However, the onset of cardiovascular disease usually begins later in life, and so our study provides an opportunity to study normal variation in these traits in premorbid adolescents. In addition, the concentration of uric acid, ferritin and a number of liver enzymes ( $\gamma$-glutamyltransferase [GGT] and alanine aminotransferase [ALT]) that are risk factors for obesity, cardiovascular disease, diabetes and the metabolic syndrome were examined. Uric acid has been shown to be associated with the metabolic syndrome [24], while serum GGT and ALT, which have been shown to be correlated [25], have been associated with cardiovascular disease [26, 27], hypertension and diabetes [27, 28]. The sample was also measured for weight and height, and hence BMI. We believe this to be the first mitochondrial association study of quantitative traits to be undertaken using family data and we present herein a method, which has been implemented in the freely available program Sib-Pair, for carrying out such a study. 
Table 1 Results from previous mitochondrial association studies of type 2 diabetes and the metabolic syndrome

\begin{tabular}{|c|c|c|c|c|c|}
\hline Study & Population & Study design & No. of individuals & $\begin{array}{l}\text { Associated } \\
\text { variant }\end{array}$ & Study findings \\
\hline $\begin{array}{l}\text { Poulton et al., } \\
2002[13]\end{array}$ & UK & $\begin{array}{l}\text { Type } 2 \text { diabetes, } \\
\text { case-control }\end{array}$ & 460 & $\operatorname{mt} 16189$ & $\begin{array}{l}\text { Weak association }(p=0.048 \text {, OR } 1.61 \text {, } \\
95 \% \text { CI } 1.0-2.7)\end{array}$ \\
\hline $\begin{array}{l}\text { Kim et al., } \\
2002[14]\end{array}$ & Korean & $\begin{array}{l}\text { Association study } \\
\text { of diabetes-related } \\
\text { traits in non-diabetics }\end{array}$ & 160 & mt16189 & $\begin{array}{l}\text { Significant association with fasting } \\
\text { glucose levels }(p=0.036) \text { and } \\
\text { BMI }(p=0.019)\end{array}$ \\
\hline $\begin{array}{l}\text { Weng et al., } \\
2005[15]\end{array}$ & Chinese & $\begin{array}{l}\text { Case-control study } \\
\text { of the metabolic } \\
\text { syndrome }\end{array}$ & 615 & $\operatorname{mt} 16189$ & $\begin{array}{l}\text { Significant association with the } \\
\text { metabolic syndrome }(p=0.006), \\
\text { fasting glucose levels }(p=0.023) \\
\text { and type } 2 \text { diabetes }(p=0.037)\end{array}$ \\
\hline $\begin{array}{l}\text { Chinnery et al., } \\
2005[16]\end{array}$ & $\begin{array}{l}\text { UK/ } \\
\text { European }\end{array}$ & $\begin{array}{l}\text { Type } 2 \text { diabetes, } \\
\text { case-control and } \\
\text { meta-analysis }\end{array}$ & $\begin{array}{l}992 \text { cases and } 1,500 \\
\text { controls. } 1,455 \text { cases } \\
\text { and } 3,132 \text { controls } \\
\text { in meta-analysis }\end{array}$ & $\begin{array}{r}16189-16193 \\
\text { poly-C tract }\end{array}$ & $\begin{array}{l}\text { No association in UK case-control } \\
\text { study. No association in meta- } \\
\text { analysis. OR } 1.16(95 \% \\
\text { CI } 0.94-1.44)\end{array}$ \\
\hline $\begin{array}{l}\text { Mohlke et al., } \\
2005 \text { [17] }\end{array}$ & Finnish & $\begin{array}{l}\text { Case-control of type } 2 \\
\text { diabetes and related } \\
\text { traits. Haplogroup } \\
\text { based. }\end{array}$ & $\begin{array}{l}762 \text { cases, } 402 \\
\text { controls and } \\
465 \text { offspring } \\
\text { of genotyped } \\
\text { females }\end{array}$ & Haplogroup J & $\begin{array}{l}\text { Haplogroup J weakly associated with } \\
\text { type } 2 \text { diabetes }(\mathrm{OR} 1.69, p=0.045) \\
\text { Increased when individuals with } \\
\text { affected fathers were removed } \\
(\text { OR } 1.77, p=0.045)\end{array}$ \\
\hline $\begin{array}{l}\text { Cristim et al., } \\
2006 \text { [19] }\end{array}$ & $\begin{array}{l}\text { White- } \\
\text { Brazilian }\end{array}$ & $\begin{array}{l}\text { Case-control of type } 2 \\
\text { diabetes }\end{array}$ & $\begin{array}{l}347 \text { cases, } \\
350 \text { controls }\end{array}$ & $\begin{array}{l}\text { Haplogroup } \\
\mathrm{J} \text { and } \\
\text { haplogroup } \mathrm{T}\end{array}$ & $\begin{array}{l}\text { Haplogroup J associated with type } 2 \\
\text { diabetes (OR } 3.1,95 \% \text { CI } 1.5-6.5 \text {, } \\
p=0.003 \text { ) and haplogroup T } \\
\text { associated (OR } 2.3,95 \% \\
\text { CI } 1.2-4.2, p=0.012)\end{array}$ \\
\hline $\begin{array}{l}\text { Saxena et al., } \\
2006[21]\end{array}$ & $\begin{array}{l}\text { Swedish, } \\
\text { Canadian, } \\
\text { Polish, US }\end{array}$ & $\begin{array}{l}\text { Type } 2 \text { diabetes } \\
\text { case-control and also } \\
\text { related metabolic } \\
\text { traits }\end{array}$ & $\begin{array}{l}\text { 3,304 cases, } \\
3,304 \text { controls }\end{array}$ & mt12612 & $\begin{array}{l}\text { No overall significant association. } \\
\text { mt12612 was associated in the } \\
\text { Polish population }(p=0.02) \text {. } \\
\text { No association with BMI or } \\
\text { cholesterol }\end{array}$ \\
\hline $\begin{array}{l}\text { Fuku et al., } \\
2007[20]\end{array}$ & $\begin{array}{l}\text { Japanese/ } \\
\text { Korean }\end{array}$ & $\begin{array}{l}\text { Diabetes, case-control. } \\
\text { Haplogroup based }\end{array}$ & $\begin{array}{r}2,021 \text { cases and } \\
2,250 \text { controls }\end{array}$ & $\begin{array}{l}\text { Haplogroup } \\
\text { N9a }\end{array}$ & $\begin{array}{l}\text { Haplogroup N9a significantly } \\
\text { associated with protection against } \\
\text { type } 2 \text { diabetes (OR } 0.55,95 \% \\
\text { CI } 0.40-0.75, p=0.002 \text { ) }\end{array}$ \\
\hline $\begin{array}{l}\text { Chinnery et al., } \\
\text { 2007[42] }\end{array}$ & UK & $\begin{array}{l}\text { Type } 2 \text { diabetes, } \\
\text { case-control. } \\
\text { Haplogroup } \\
\text { based }\end{array}$ & $\begin{array}{l}897 \text { cases, } 1,010 \\
\text { controls }\end{array}$ & None & $\begin{array}{l}\text { No evidence to suggest any } \\
\text { European haplogroups play a } \\
\text { role in increasing disease } \\
\text { susceptibility }\end{array}$ \\
\hline
\end{tabular}

\section{Methods}

Sample Families consisted of adolescent twins and their siblings who had been recruited as part of two overlapping studies into the genetic and environmental influences on cognition [29] and melanoma risk factors [30]. Twins between the ages of 12 and 16 years and their families were recruited by contacting principals of schools in the Brisbane area and through media appeals. For the melanoma study, twins were recruited as close as possible to their 12th and 14th birthdays, and for the cognition study, twins were measured as close as possible to their 16th birthday. For all of the studies, participants gave informed consent to the questionnaire, interview and collection of blood. The studies were approved by the Queensland Institute of Medical Research Human Research Ethics Committee.
Table 2 gives the breakdown of the number of individuals measured at each time point and the overlap between the groups. The sample has been shown to be representative of the general Queensland population with respect to cognition [29] and skin mole counts [31]. Further information on the sample, including recruitment strategy, have been described previously [31,32].

A total of 2,484 individuals were measured on at least one visit. Of those who had been measured at least once, 2,179 (87.72\%) had been genotyped for a set of 69 mitochondrialtagging single-nucleotide polymorphisms (SNPs). The sample was divided into three separate age groups that corresponded with the time of the visit. The first group contained all individuals $<13$ years of age on their first visit, the second group contained all those $<15$ years but $>13$ years at the time of their first or second visit, and the final group 
Table 2 Breakdown of zygosity by age group and overlap between groups

DZ, dizygotic;

MZ, monozygotic

\begin{tabular}{llrllrrr}
\hline Measurement occasion & $\begin{array}{l}\text { No. of } \\
\text { families }\end{array}$ & $\begin{array}{l}\text { MZ } \\
\text { pairs }\end{array}$ & $\begin{array}{l}\text { DZ } \\
\text { pairs }\end{array}$ & $\begin{array}{l}\text { Non-twin } \\
\text { siblings }\end{array}$ & $\begin{array}{l}\text { No. of } \\
\text { males }\end{array}$ & $\begin{array}{l}\text { No. of } \\
\text { females }\end{array}$ & $\begin{array}{l}\text { Total no. of } \\
\text { individuals }\end{array}$ \\
\hline Age & & & & & & & \\
12 years & - & 44 & 92 & 63 & 177 & 158 & 335 \\
14 years & - & 4 & 14 & 112 & 83 & 65 & 148 \\
16 years & - & 80 & 90 & 233 & 278 & 295 & 573 \\
12 and 14 years & - & 43 & 79 & 39 & 136 & 147 & 283 \\
12 and 16 years & - & 2 & 11 & 14 & 23 & 17 & 40 \\
14 and 16 years & - & 32 & 43 & 53 & 96 & 107 & 203 \\
12,14 and 16 years & - & 46 & 176 & 28 & 231 & 241 & 472 \\
Total & & & & & & & 1,024 \\
At any age & 908 & 251 & 505 & 542 & 1,030 & 2,054 \\
At 12 years & 561 & 135 & 358 & 144 & 567 & 563 & 1,130 \\
At 14 years & 570 & 125 & 312 & 232 & 546 & 560 & 1,106 \\
At 16 years & 640 & 160 & 320 & 328 & 628 & 660 & 1,288 \\
\hline
\end{tabular}

contained all remaining individuals. A further analysis was carried out using the average of an individual's measurements if they had been measured on more than one occasion. To reduce bias due to their being greater numbers of individuals in particular age groups, and different means and SDs in each age group, the standardised residuals after adjusting for age and sex were averaged over the three age groups. Ancestry data were collected as part of the study, and a total of 24 families with non-European ancestry were removed from the analysis. A total of 908 families were included in the analysis

Genotyping The details of the genotyping have been described elsewhere [33, 34], but briefly, Saxena et al. [21] identified $64 \mathrm{mtSNPs}$ that tag all mitochondrial variants of $>1 \%$ frequency in the European population with an $r^{2}$ of 0.8 . For this study, 61 of the 64 tagSNPs were genotyped as well as an additional nine SNPs, which tag the three nontyped tagSNPs from Saxena et al. as well as further variation at $r^{2}>0.8$, that otherwise required the use of multi-SNP haplotypes using a method described in a previous study [33]. A common D-loop variant, mt16189, which has previously been implicated as being associated with type 2 diabetes was also genotyped. This gave a total of 71 SNPs, but two were found to be monomorphic in our sample, leaving 69 SNPs in the final analysis. SNPs were typed using iPLEX Gold chemistry (Sequenom, San Diego, CA, USA) and analysed using a Sequenom MassARRAY Compact Mass Spectrometer. After PCR reactions, a twostep 200 short cycles program was used for a post-PCR extension reaction. The iPLEX reaction products were spotted on a SpectroChip (Sequenom) and data were processed and analysed by MassARRAY TYPER 3.4 software (Sequenom).
All SNPs had a high call rate $(>95 \%)$. There were 62 $(0.03 \%)$ 'heterozygous' calls, indicating that there is little heteroplasmy in the sample. Some of those calls could be attributed to genotyping error. Heterozygous calls were treated as missing for the purposes of this study. Any individual with $>5 \%$ missing genotypes (two individuals) was removed from the analysis.

The maternal inheritance pattern of mitochondria means that when a mutation occurs, it is transmitted in a particular background of variants and therefore is linked to all of them. These sets of linked variants are known as haplogroups. It has been previously shown by us [33] and others [21] that the tagging SNPs genotyped here can be used to tag all the major European haplogroups. Using a linear discriminant function analysis method described by us previously [33], each haplotype was assigned to a haplogroup. Because of missing genotypes, a small number of haplotypes $(<1 \%)$ could not unambiguously be assigned to haplogroups.

Traits The sample was analysed for a total of nine traits. Seven of these were measures of the concentration of a number of biochemical markers: non-fasting glucose blood level, and serum HDL-cholesterol, GGT, triacylglycerol, ALT, uric acid and ferritin. Height and BMI were also tested for association. Further information regarding the measurement of these variables have been described [25, 35]. Participants were not instructed to fast before measurements were taken. This might have affected the measurements of some traits, but most particularly blood glucose and HDLcholesterol, which can be affected by the amount of carbohydrate and fat, respectively, consumed in a recent meal. As such, the variance of these traits will be affected by the variability in time to the last meal of the individuals. All traits that deviated from normality (ALT, GGT, ferritin 
and BMI) were $\log _{10}$ transformed to ensure they had a normal distribution. Individuals with a $z$ score $>3.5$ were excluded from the analysis for that trait. The number of individuals excluded for a particular trait in a specific age group ranged from 0 (height and BMI in 12 year age group) to 11 (ALT in the 16 year age group).

Analysis Simple regression of a trait on mitochondrial genotype is not suitable when using family data due to nuclear genetic sharing between family members. To account for the nuclear effects, a linear mixed model is used to model the inheritance of both mitochondrial and nuclear genetic effects. The full model is

$\mathrm{y}=\mu+\beta \mathrm{x}+\mathrm{Zu}+\mathrm{e}$

where $\mathrm{y}$ is a vector of phenotypes and $\mu$ is the mean. The mitochondrial inheritance is modelled as a fixed effect $(\beta)$, where $\mathrm{x}$ is a vector of mitochondrial genotype indicators and $\beta$ is a scalar containing an estimate of the effect of the mitochondrial variant. The nuclear genetic inheritance is modelled with a random effect $\mathrm{Zu}$, where $\mathrm{Z}$ is a matrix relating individuals to phenotypes and $u$ is a vector of nuclear additive polygenetic effects and $\mathrm{e}$ is a vector of residuals. The random effects $u$ and e are assumed to be distributed as multivariate normal, where $u \sim N\left(0, A \sigma_{a}^{2}\right)$, and $e \sim N\left(0, I \sigma_{e}^{2}\right)$, where $\mathrm{A}$ is the standard additive genetic relationship matrix, and $\mathrm{I}$ is an identity matrix. The heritability can be estimated as $\sigma_{a}^{2} /\left(\sigma_{a}^{2}+\sigma_{e}^{2}\right)$. The model above fits an AE variance components model ( $\mathrm{u}$ is the additive genetic variance and $\mathrm{e}$ is the environmental variance) which assumes that the phenotypic variance in the sample can be explained by additive genetic variance (A) and unique environmental variance (E) (u represents additive genetic variance and $\mathrm{e}$ is the environmental variance in the full model). This model assumes that there is no variance due to family members, in particular twin pairs, sharing common environmental factors. If such common environmental variance does exist, it will be confounded with additive genetic variance, leading to an upward bias of heritabilities. The model was fitted using the program Sib-Pair (www.qimr.edu.au/davidD/index. html\#sib-pair, accessed 28 April 2009) via the 'mit' command, and the effect of the mitochondrial variant was estimated using maximum-likelihood estimation.

Two SNPs were found to be monomorphic in the 12 and 14 year age groups, meaning that there were only 67 SNPs tested for association. The effective number of independent tests being carried out was estimated by calculating the linkage disequilibrium between all SNPs and their correlation with haplogroups using the SNPSpD program [36] and using the previously described method [37]. The estimated number of independent tests was 65 . The number of independent traits, 8.1, was estimated using the previously described method [38]. Accordingly, the experiment-wide significance level was set at $p=6.85 \times 10^{-4}(5 \%$ significance level with a Bonferroni correction for the 73 tests, 65 variants and eight traits, being carried out).

\section{Results}

The breakdown of and overlap between the groups is shown in Table 2. The number of individuals included in the analysis of each trait and the means and SDs for each trait in each age group are given in Table 3. The number of families included in each analysis is also presented. All traits were significantly different across the different age groups at the 0.001 level (paired $t$ test), except for GGT, which was not significantly different between the 12 and 14 year age groups $(p=0.106)$, and ferritin $(p=0.132$ for 14-16 year comparison).

The heritability estimates for each trait in our sample are high (Table 4), due to the heritability being estimated under an AE model, and there are strong phenotypic correlation across the three measurement time points [25, 35, 39].

Table 5 shows the most significant associations for each trait in the 12, 14 and 16 year age groups. Between the three analyses of the different age groups, there was only one variant for one trait that was found to be significant after correction for multiple testing - mt14365 with triacylglycerol in the 12 year age group. This association was not found in the other two groups. The $p$ values for the association between mt14365 and triacylglycerol in the two other age groups were 0.1416 and 0.3412 , respectively. Figure 1 shows a $Q-Q$ plot of the observed vs expected test statistic for the 77 tests performed for triacylglycerol levels in the 12 year age group. It shows that there is an increase in the test statistic at the high end of the distribution above that which would be expected by chance. This increase was not found in the other age groups. This SNP did have the lowest $p$ value in the analysis of the average of the phenotypes. Several other variants that approached significance in one group were non-significant in other groups, indicating that they are most likely approaching significance by chance. $Q-Q$ plots for all variants with each of the nine traits in the 12,14 and 16 year age groups are shown in the Electronic supplementary material (ESM) Figs 1, 2 and 3 , respectively. Excluding the increase noted in the 12 year group for triacylglycerol, the distribution of the test statistic follows the expected $\chi^{2}$ distribution.

Haplogroup W was the most significantly associated variant with uric acid in both the 14 and 16 year groups, but the association is not significant after multiple testing. After correction for multiple testing, there appear to be no significant associations between any of the traits examined here and the major European haplogroups. 


\begin{tabular}{|c|c|c|c|c|}
\hline & 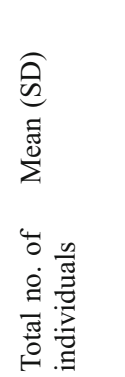 & 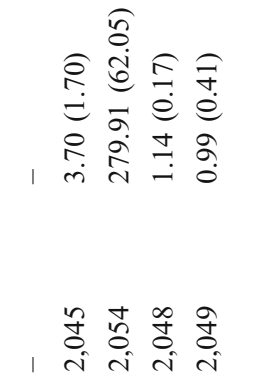 & 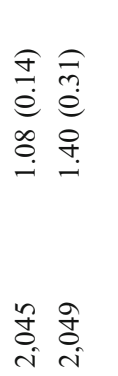 & 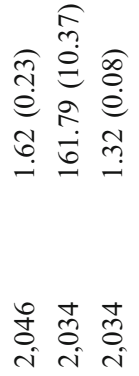 \\
\hline & 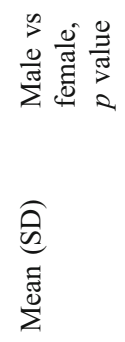 & 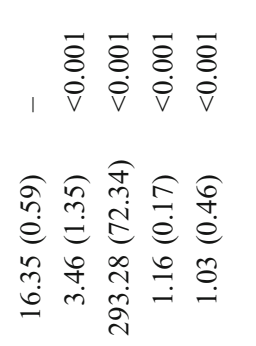 & 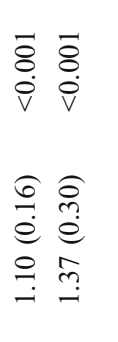 & 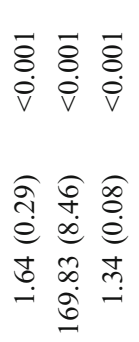 \\
\hline 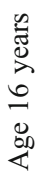 & 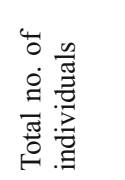 & 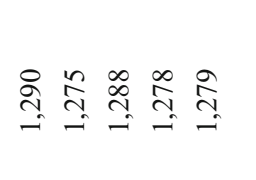 & 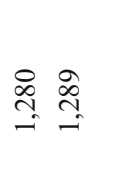 & 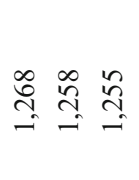 \\
\hline & 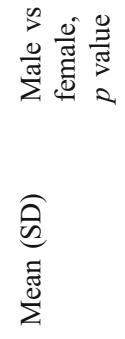 & 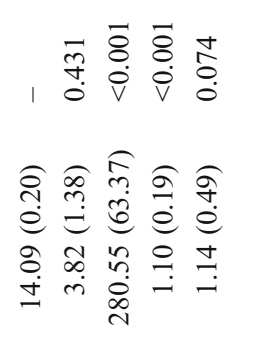 & 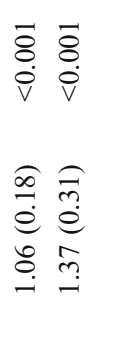 & 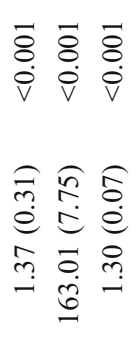 \\
\hline 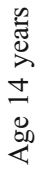 & 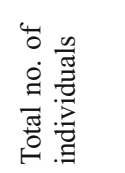 & 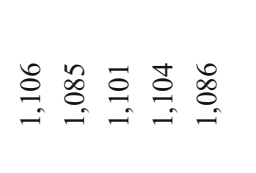 & $\stackrel{0}{\infty} \stackrel{0}{0}$ & $\begin{array}{l}\overrightarrow{0} \\
0\end{array}$ \\
\hline & 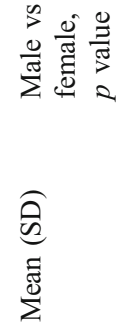 & 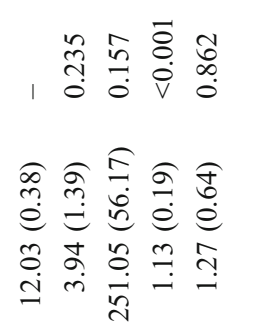 & 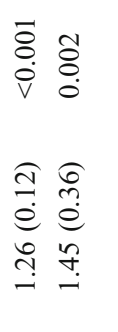 & 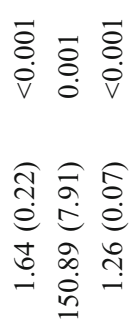 \\
\hline 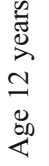 & 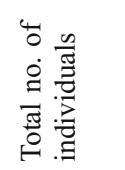 & 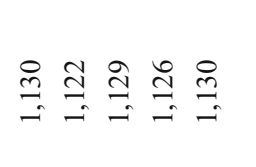 & $\stackrel{\infty}{\stackrel{\infty}{=}} \underset{=}{=}$ & 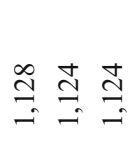 \\
\hline & & 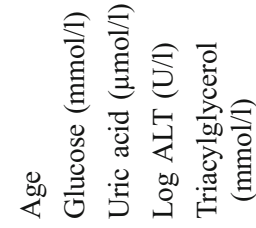 & $\overline{\mathrm{D}}$ & 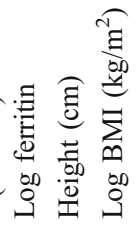 \\
\hline
\end{tabular}


Table 4 Estimates of heritability of traits across the three different age groups

\begin{tabular}{lccc}
\hline Trait & \multicolumn{3}{l}{ Heritability (\%) } \\
\cline { 2 - 4 } & Age 12 years & Age 14 years & Age 16 years \\
\hline Glucose & 68 & 77 & 73 \\
Uric acid & 83 & 79 & 76 \\
ALT & 42 & 43 & 43 \\
Triacylglycerol & 49 & 51 & 53 \\
GGT & 72 & 73 & 76 \\
HDL-cholesterol & 87 & 85 & 80 \\
Ferritin & 34 & 70 & 63 \\
Height & 91 & 87 & 85 \\
BMI & 87 & 83 & 85 \\
\hline
\end{tabular}

Heritability was estimated by variance components analysis where phenotypic variance was decomposed into additive genetic and environmental variance

The frequencies of all SNPs and haplogroups, and their results with each trait in the analysis of the average of the phenotypes are given in ESM Table 1.

\section{Discussion}

We have carried out a family-based mitochondrial association study on a number of traits related to type 2 diabetes and the metabolic syndrome in adolescent twins. The maternal inheritance pattern of mitochondria means that mitochondrial variants do not segregate in families in the same way as autosomal variants, and all children in a family will carry the same mtDNA sequence. This means that a family-based design will have less power than an equivalent mitochondrial association study using unrelated individuals, although some of the loss of power will be offset due to the increased accuracy of trait measurement that is achieved when many family members with the same genotype are measured. In spite of this loss of power, there are some advantages in using family-based data in such a study.

For this study, we have genotyped all family members for whom phenotypic data were collected. However, given that all family members share the same mitochondrial genome, future studies would only require genotyping of one child per family, while the phenotypes of all siblings could be included. Therefore, for the same amount of genotyping, more power is obtained if the number of phenotypes is not a restriction.

Phenotypic similarities between family members will not only be due to sharing mitochondrial variants, but also because they share large portions of the nuclear genome in common, and this needs to be taken into account in looking for potential associations. Because the family resemblance is controlled for, the error variance is decreased, increasing
Table 5 The most significantly associated variant for each trait in each age group

\begin{tabular}{|c|c|c|c|}
\hline Trait/age group & Most associated variant & $p$ value & $\beta(\mathrm{SE})^{\mathrm{a}}$ \\
\hline \multicolumn{4}{|l|}{ Glucose } \\
\hline 12 years & Haplogroup J & 0.026 & $0.34(0.15)$ \\
\hline 14 years & $\mathrm{mt} 5465$ & 0.019 & $1.24(0.52)$ \\
\hline 16 years & $\mathrm{mt} 4336$ & 0.002 & $-0.99(0.33)$ \\
\hline Average & $\mathrm{mt} 4336$ & 0.005 & $-0.40(0.12)$ \\
\hline \multicolumn{4}{|l|}{ Uric acid } \\
\hline 12 years & $\mathrm{mt} 9716$ & 0.043 & $-0.03(0.01)$ \\
\hline 14 years & Haplogroup W & 0.004 & $-0.04(0.01)$ \\
\hline 16 years & Haplogroup W & 0.001 & $-0.06(0.02)$ \\
\hline Average & Haplogroup W & 0.015 & $-0.51(0.10)$ \\
\hline \multicolumn{4}{|l|}{ ALT $(\log )$} \\
\hline 12 years & mt11377 & 0.015 & $0.06(0.03)$ \\
\hline 14 years & $\mathrm{mt} 930$ & 0.018 & $0.01(0.01)$ \\
\hline 16 years & Haplogroup U & 0.041 & $-0.01(0.01)$ \\
\hline Average & $\mathrm{mt} 3010$ & 0.064 & $-0.13(0.02)$ \\
\hline \multicolumn{4}{|l|}{ Triacylglycerol } \\
\hline 12 years & $\mathrm{mt} 14365$ & 0.001 & $0.60(0.17)$ \\
\hline 14 years & mt6776 & 0.016 & $-0.06(0.02)$ \\
\hline 16 years & $\mathrm{mt} 10084$ & 0.094 & $-0.32(0.16)$ \\
\hline Average & mt14365 & 0.010 & $0.52(0.10)$ \\
\hline \multicolumn{4}{|l|}{ GGT $(\log )$} \\
\hline 12 years & mt9123 & 0.002 & $-0.09(0.03)$ \\
\hline 14 years & mt10398 & 0.010 & $-0.03(0.01)$ \\
\hline 16 years & Haplogroup I & 0.012 & $0.07(0.03)$ \\
\hline Average & mt8869 & 0.030 & $-1.00(0.22)$ \\
\hline \multicolumn{4}{|l|}{ HDL-cholesterol } \\
\hline 12 years & mt13734 & 0.012 & $-0.52(0.21)$ \\
\hline 14 years & mt14182 & 0.005 & $-0.17(0.06)$ \\
\hline 16 years & mt13708 & 0.032 & $0.06(0.03)$ \\
\hline Average & mt3394 & 0.016 & $-0.55(0.12)$ \\
\hline \multicolumn{4}{|l|}{ Ferritin (log) } \\
\hline 12 years & mt13965 & 0.023 & $0.23(0.10)$ \\
\hline 14 years & mt3394 & 0.020 & $0.16(0.07)$ \\
\hline 16 years & $\mathrm{mt} 750$ & 0.064 & $-0.09(0.03)$ \\
\hline Average & $\mathrm{mt} 5460$ & 0.026 & $0.25(0.06)$ \\
\hline \multicolumn{4}{|l|}{ Height } \\
\hline 12 years & mt1189 & 0.015 & $2.60(1.06)$ \\
\hline 14 years & mt15884 & 0.003 & $-4.83(1.61)$ \\
\hline 16 years & mt9123 & 0.004 & $2.87(1.01)$ \\
\hline Average & Haplogroup K & 0.005 & $0.28(0.06)$ \\
\hline \multicolumn{4}{|l|}{ BMI (log) } \\
\hline 12 years & $\mathrm{mt} 8705$ & 0.003 & $0.22(0.07)$ \\
\hline 14 years & mt1189 & 0.009 & $0.06(0.02)$ \\
\hline 16 years & $\mathrm{mt} 7028$ & 0.008 & $0.03(0.01)$ \\
\hline Average & mt14365 & 0.010 & $0.56(0.10)$ \\
\hline
\end{tabular}

${ }^{\mathrm{a}} \beta$ values for the average age group are given in SDs 


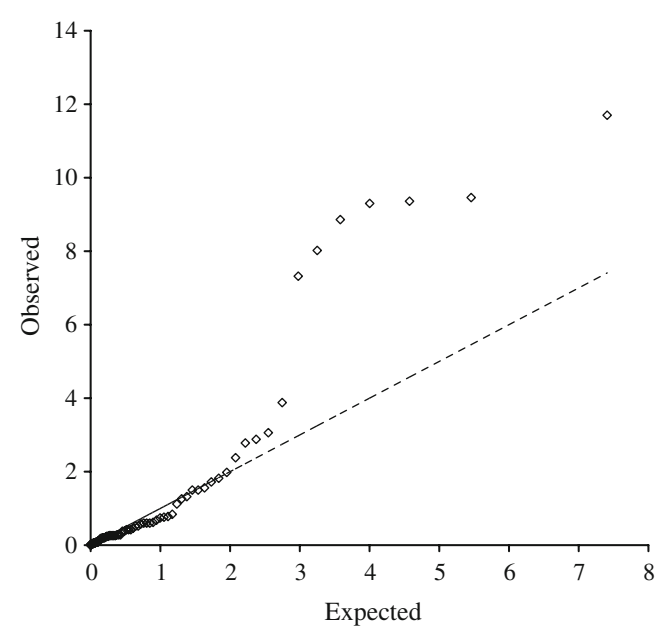

Fig. $1 Q-Q$ plot of observed vs expected distribution of test statistic for triacylglycerol in the 12 year age group

the power of the study. Until now, mitochondrial association studies have focused on case-control data. However, many large family cohorts have been previously collected for linkage analysis and are now being genotyped using the latest SNP chips for association studies. The latest of these SNP chips contain a number of common mitochondrial variants. In order for a proper test of association with mitochondrial variants to be carried out, a method similar to the one described here would need to be used. The implementation of this methodology in Sib-Pair will allow such analyses to be carried out efficiently in the future.

In spite of the loss of optimal power because of relatedness, our study still has at least equivalent power to a study of just one individual per family. The overall analysis contains data from 908 families, so our study has almost $100 \%$ power to detect a hypothetical mitochondrial variant with a frequency of $1 \%$, which explains $5 \%$ of the variance of a quantitative trait, and $\sim 50 \%$ power to detect a variant explaining $1 \%$ of the variance [33].

We find no evidence to suggest that common European mitochondrial variants contribute to variation in metabolic traits in adolescent twins. We have typed the mt16189 polymorphism, haplogroup J and $\mathrm{mt} 12612$, all of which have been previously posited as potentially being associated with type 2 diabetes, but find no evidence of their playing a role in normal variation in metabolic traits. However, as the association with type 2 diabetes was not directly tested, the hypothesis that these polymorphisms, or other mitochondrial variants increase susceptibility cannot be rejected.

There were no strong associations across age groups; however, this is not inconsistent with previous reports, which have suggested that different genetic factors may act upon these phenotypes at different times [25, 35]. The increased number of large test statistics relative to the expected distribution for the association with triacylglycerol suggests that common mitochondrial variants may influence this trait in early adolescence. However, this result will need to be replicated in further studies with even larger sample sizes than this study. Such further studies may also lead to the discovery of associations with more modest effects than can be detected here.

The traits being analysed here were studied because they are found to be increased in individuals with the metabolic syndrome and diabetes. To the best of our knowledge, none of the individuals analysed in our adolescent sample suffered from these conditions. However, the incidence of these conditions increases with age and so the hypothesis that common mitochondrial variants contribute to disease risk cannot be rejected here. It is possible that onset of disease might be a result of geneenvironment interactions that act over time and that certain mitochondrial variants predispose to disease only after certain environmental factors (e.g. diet) have acted over a period of time. Such an interaction may not be picked up in a study of adolescents. In addition, we have not examined genes encoding other proteins in the OXPHOS complex, or their potential interaction with mitochondrial variants in this study as potential contributors to variation in these traits.

It has previously been proposed that the gradual accumulation of mutations in mtDNA may contribute to age-related diseases such as diabetes [10]. Current mitochondrial association studies cannot test this hypothesis as they only test for the association between the consensus mitochondrial genotype in the tissue under study with a disease or quantitative phenotype. It has been shown that less heteroplasmy can be detected in blood DNA than other tissues [21, 40], and so even if there are mutant mitochondria predisposing to disease, they may not be detected. Another limitation of mitochondrial association studies is that they are potentially confounded by the nuclear background as there is significant cross-talk between the two systems. Some of the most convincing evidence for a role of mtDNA in metabolic phenotypes comes from studies of mice with identical nuclear genomes, but different mitochondrial genomes [11]. In this regard, twin studies may prove to be a valuable resource in trying to uncover the role of mitochondria in disease. As monozygotic twins have identical nuclear genomes, the detection of differences in mtDNA caused by proliferation of somatically mutant mtDNAs could potentially explain phenotypic discordance between co-twins. This approach was used by Detjen et al. [41] to test whether phenotypic variability between monozygotic twins in the autosomal dominant disorder neurofibromatosis type I was due to differences in mtDNA. Such a method, when applied to large-scale association studies of quantitative phenotypes could reduce the potential for confounders and provide 
more direct evidence of a role of mtDNA in common complex diseases.

Acknowledgements We are grateful to the twins and their families for their generous participation in these studies. We would like to thank A. Eldridge and M. Grace for the collection of data and M. Campbell and A. Henders for managing sample processing and preparation, and B. Cornes for assistance with the BMI data. Financial support was provided by grants from the National Health and Medical Research Council (241944, 389875 and 389892). E. M. Byrne is supported by University of Queensland IPRS and UQILAS Awards and by a QIMR Dr Diana Cavaye award. P. M. Visscher is a National Health and Medical Research Council of Australia (NHMRC) Principal Research Fellow (Grant ID 442915), G. W. Montgomery is a NHMRC Senior Research Fellow (Grant ID 339446), and A. F. McRae is supported by NHMRC Postdoctoral Fellowship \#496719.

Conflict of interest The authors declare that there is no duality of interest associated with this manuscript.

\section{References}

1. Petersen KF, Befroy D, Dufour S et al (2003) Mitochondrial dysfunction in the elderly: possible role in insulin resistance. Science 300:1140-1142

2. Petersen KF, Dufour S, Befroy D, Garcia R, Schulman GI (2004) Impaired mitochondrial activity in the insulin-resistant offspring of patients with type 2 diabetes. N Engl J Med 350:664-671

3. Mootha VK, Lindgren CM, Eriksson KF et al (2003) PGC-1- $\alpha$ responsive genes involved in oxidative phosphorylation are coordinately downregulated in human diabetes. Nat Genet 34: 267-273

4. Patti ME, Butte AJ, Crunkhorn S et al (2003) Coordinated reduction of genes of oxidative metabolism in humans with insulin resistance and diabetes: potential role of PGC1 and NRF1. Proc Natl Acad Sci U S A 100:8466-8471

5. Maechler P, Carobbio S, Rubi B (2006) In beta-cells, mitochondria integrate and generate metabolic signals controlling insulin secretion. Int J Biochem Cell Biol 38:696-709

6. Ritov VB, Menshikova EV, He J, Ferrell RE, Goodpaster BH, Kelley DE (2005) Deficiency of subsarcolemnal mitochondria in obesity and type 2 diabetes. Diabetes 54:8-14

7. Alcolado JC, Laji K, Gill-Randall R (2002) Maternal transmission of diabetes. Diabet Med 19:89-98

8. Barrett TG (2001) Mitochondrial diabetes, DIDMOAD and other inherited diabetes syndromes. Best Pract Res Clin Endocrinol Metab 15:325-343

9. van den Ouweland JM, Lemkes HH, Ruitenbeek W et al (1992) Mutation in mitochondrial tRNA(Leu)(UUR) gene in a large pedigree with maternally transmitted type 2 diabetes mellitus and deafness. Nat Genet 1:368-371

10. Wallace DC (2007) Why do we still have a maternally inherited mitochondrial DNA? Insights from evolutionary medicine. Annu Rev Biochem 76:781-821

11. Pravenec M, Hyakukoku M, Houstek J et al (2007) Direct linkage of mitochondrial genome variation to risk factors for type 2 diabetes in conplastic strains. Genome Res 17:1319-1326

12. Maechler P, Wollheim CB (2001) Mitochondrial function in normal and diabetic beta-cells. Nature 414:807-812

13. Poulton J, Luan J, Macaulay V, Hennings S, Mitchell J, Wareham NJ (2002) Type 2 diabetes is associated with a common mitochondrial variant: evidence from a population-based casecontrol study. Hum Mol Genet 11:1581-1583
14. Kim JH, Park KS, Cho YM et al (2002) The prevalence of mitochondrial DNA 16189 variant in non-diabetic Korean adults and its association with higher fasting glucose and body mass index. Diabet Med 19:681-684

15. Weng SW, Liou CW, Lin TK et al (2005) Association of mitochondrial DNA 16189 variant with metabolic syndrome in Chinese adults. J Clin Endocrinol Metab 90:5037-5040

16. Chinnery PF, Elliott HR, Patel S et al (2005) Role of the mitochondrial DNA 16184-16193 poly-C tract in type 2 diabetes. Lancet 366:1650-1651

17. Mohlke KL, Jackson $\mathrm{Au}$, Scott LJ et al (2005) Mitochondrial polymorphisms and susceptibility to type 2 diabetes-related traits in Finns. Hum Genet 118:245-254

18. Raule N, Sevini F, Santoro A, Altilia S, Altilia A, Franceschi C (2007) Association studies on human mitochondrial DNA: methodological aspects and results in the most common agerelated diseases. Mitochondrion 7:29-38

19. Crispim D, Canani LH, Gross JL, Tschiedel B, Souto KEP, Roisenberg I (2006) The European-specific mitochondrial cluster $\mathrm{J} / \mathrm{T}$ could confer an increased risk of insulin-resistance and type 2 diabetes: an analysis of the m.4216T $>C$ and $\mathrm{m} .4917 \mathrm{~A}>\mathrm{G}$ variants. Ann Hum Genet 70:488-495

20. Fuku N, Park KS, Yamada Y et al (2007) Mitochondrial haplogroup N9a confers resistance against Type 2 diabetes in Asians. Am J Hum Genet 80:407-415

21. Saxena R, de Bakker PI, Singer K et al (2006) Comprehensive association testing of common mitochondrial DNA variation in metabolic disease. Am J Hum Genet 79:54-61

22. Kannel WB (2000) The Framingham Study: its 50-year legacy and future promise. J Atheroscler Thromb 6:60-66

23. Beekman M, Heijmans BT, Martin NG et al (2002) Heritabilities of apolipoprotein and lipid levels in three countries. Twin Res 5:87-97

24. Liese AD, Hense HW, Lowel H, Doring A, Tietze M, Keil U (1999) Association of serum uric acid with all-cause and cardiovascular disease mortality and incident myocardial infarction in the MONICA Augsburg cohort. World Health Organization Monitoring Trends and Determinants in Cardiovascular Diseases. Epidemiology 10:391-397

25. Middelberg RPS, Medland SE, Martin NG, Whitfield JB (2007) A longitudinal genetic study of uric acid and liver enzymes in adolescent twins. Twin Res Hum Gen 10:757-764

26. Pompella A, Emdin M, Passino C, Paolicchi A (2004) The significance of serum gamma-glutamyltransferase in cardiovascular diseases. Clin Chem Lab Med 42:1085-1091

27. Nannipieri M, Gonzales C, Baldi S et al (2005) Liver enzymes, the metabolic syndrome, and incident diabetes: The Mexico City diabetes study. Diabetes Care 28:1757-1762

28. Lee DH, Jacob DR, Gross M et al (2003) Gammaglutamyltransferase is a predictor of incident diabetes and hypertension: the Coronary Artery Risk Development in Young Adults (CARDIA) Study. Clin Chem 49:1358-1366

29. Wright MJ, Martin NG (2004) Brisbane Adolescent Twin Study: outline of study methods and research projects. Aust J Psychol $56: 65-78$

30. Zhu G, Duffy DL, Eldridge A et al (1999) A major quantitativetrait locus for mole density is linked to the familial melanoma gene CDKN2A: a maximum-likelihood combined linkage and association analysis in twins and their sibs. Am J Hum Genet 65:483-492

31. Zhu G, Montgomery GW, James MR et al (2007) A genome-wide scan for naevus count: linkage to CDKN2A and to other chromosome regions. Eur J Hum Genet 15:94-102

32. Duffy DL, Montgomery GW, Chen W et al (2007) A threesingle-nucleotide polymorphism haplotype in intron 1 of OCA2 explains most human eye-color variation. Am J Hum Genet $80: 241-252$ 
33. McRae AF, Byrne EM, Zhao ZZ et al (2008) Power and SNP tagging in whole mitochondrial genome association studies. Genome Res 18:911-917

34. Byrne EM, McRae AF, Zhao ZZ et al (2008) The use of common mitochondrial variants to detect and characterise population structure in the Australian population: implications for genomewide association studies. Eur J Hum Genet 16:1396-1403

35. Middelberg RPS, Martin NG, Whitfield JB (2007) A longitudinal genetic study of plasma lipids in adolescent twins. Twin Res Hum Genet 10:127-135

36. Nyholt DR (2004) A simple correction for multiple testing for SNPs in linkage disequilibrium with each other. Am J Hum Genet 74:765-769

37. Li J, Ji L (2005) Adjusting multiple testing in multilocus analyses using the eigenvalues of a correlation matrix. Heredity 95:221-227
38. Cheverud JM (2001) A simple correction for multiple comparisons in interval mapping genome scans. Heredity 87:52-58

39. Cornes BK, Zhu G, Martin NG (2007) Sex differences in genetic variation in weight: a longitudinal study of body mass index in adolescent twins. Behav Genet 37:648-660

40. Jazin EE, Cavelier L, Eriksson I, Oreland L, Gyllensten U (1996) Human brain contains high levels of heteroplasmy in the noncoding regions of mitochondrial DNA. Proc Natl Acad Sci U S A 93:12382-12387

41. Detjen AK, Tinschert S, Kaufmann D et al (2007) Analysis of mitochondrial DNA in discordant monozygotic twins with neurofibromatosis type 1. Twin Res Hum Genet 10:486-495

42. Chinnery PF, Mowbray C, Patel SK et al (2007) Mitochondrial DNA haplogroups and type 2 diabetes: a study of 897 cases and 1010 controls. J Med Genet 44:e80 